\title{
Break the Chain of Coronavirus Disease (Covid-19) Infection: A Review
}

\author{
Sufiyan Ahmad*, Md. Rageeb Md. Usman ${ }^{1}$, Kiran D. Baviskar ${ }^{2}$, Tushar P. Patil ${ }^{3}$ \\ *Department of Pharmacognosy, Gangamai College of Pharmacy, Nagaon, Dist. Dhule (M.S.), India. \\ ${ }^{1}$ Department of Pharmacognosy, College of Pharmacy, Chopda, Dist. Jalgaon (M.S.), India. \\ 2Department of Pharmaceutics, College of Pharmacy, Chopda, Dist. Jalgaon (M.S.), India. \\ ${ }^{3}$ Department of Pharmacology, College of Pharmacy, Chopda, Dist. Jalgaon (M.S.), India. \\ *Corresponding author's E-mail: rageebshaikh@gmail.com
}

Received: 16-07-2020; Revised: 28-09-2020; Accepted: 06-10-2020; Published on: 20-10-2020.

\begin{abstract}
In December 2019, several patients from Wuhan, China were admitted with symptoms of pneumonia. As the number of patients presenting with similar symptoms started to rise, the causative agent was eventually isolated from samples. It was initially called the 2019 novel coronavirus (2019-nCoV) and has been recently relabelled as severe acute respiratory syndrome coronavirus 2 (SARS-CoV2); the disease it causes has been named coronavirus disease 2019 (COVID-19). Coronavirus disease (COVID-19) is an infectious disease caused by a newly discovered coronavirus. special treatment. Older people, and those with underlying medical problems like cardiovascular disease, diabetes, chronic respiratory disease, and cancer are more likely to develop serious illness. The best way to prevent and slow down transmission is be well informed about the COVID-19 virus, the disease it causes and how it spreads. Protect yourself and others from infection by washing your hands or using an alcohol based rub frequently and not touching your face. The COVID-19 virus spreads primarily through droplets of saliva or discharge from the nose when an infected person coughs or sneezes, so it's important that you also practice respiratory etiquette (for example, by coughing into a flexed elbow). At this time, there are no specific vaccines or treatments for COVID-19. However, there are many ongoing clinical trials evaluating potential treatments. WHO will continue to provide updated information as soon as clinical findings become available. Since the virus is spreading worldwide, on March 31, 2020, the WHO officially described the COVID-19 outbreak as a pandemic.
\end{abstract}

Keywords: COVID-19, Causes, Prevention and control, outbreak, Review.

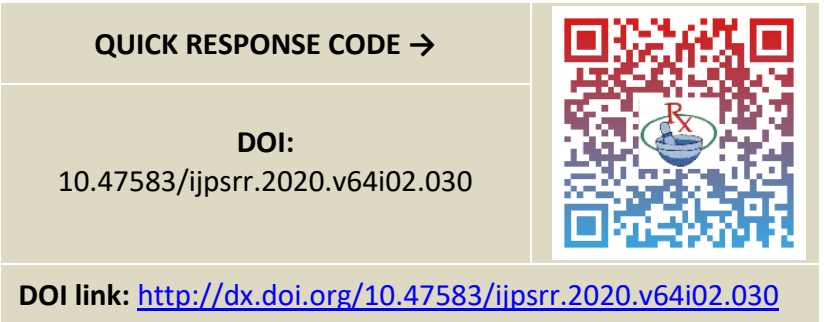

\section{INTRODUCTION}

O ver the last few decades, the world has seen the existence of new viruses that posed serious threats to global health. In late December 2019, several patients in Wuhan, China started reporting symptoms that resembled pneumonia. A new virus was identified and initially called the 2019 novel coronavirus (2019-nCoV). The World Health Organization (WHO) eventually changed the name of the virus to severe acute respiratory syndrome coronavirus 2 (SARS-CoV-2). ${ }^{1-5}$ The disease it causes has been named coronavirus disease 2019 (COVID19). The SARS-CoV is a positive-stranded RNA virus that originates from the Coronaviridae family. Other viruses from the same family include the severe acute respiratory syndrome coronavirus (SARS-CoV), which appeared in 2002, and Middle East respiratory syndrome coronavirus (MERS-CoV), which was reported in 2012. ${ }^{6}$
In response to the outbreak, the Chinese Center for Disease Control and Prevention (China CDC) dispatched a rapid response team to accompany health authorities of Hubei province and Wuhan city to con duct epidemiological and etiologic al investigations. The WHO confirmed that the outbreak of the coronavirus epidemic was associated with the Huanan South China Seafood Marketplace, but no specific animal association was identified. ${ }^{7}$ Scientists immediately started to research the source of the new coronavirus, and the first genome of COVID-19 was published by the research team led by Prof. Yong-Zhen Zhang, on 10 January 2020. ${ }^{8}$ Within 1 month, this virus spread quickly throughout China during the Chinese New Year - a period when there is a high level of human mobility among Chinese people. Although it is still too early to predict susceptible populations, early patterns have shown a trend similar to Severe Acute Respiratory Syndrome (SARS) and Middle East respiratory syndrome (MERS) coronaviruses. Susceptibility seems to be associate d with age, biological sex, and other health conditions. ${ }^{9}$ COV ID-19 has now been declared as a Public Health Emergency of International Concern by the WHO. ${ }^{10}$ Since the virus is spreading worldwide, on March 11, 2020, the WHO officially described the COVID-19 outbreak as a pandemic. 


\section{BREAK THE CHAIN OF COVID-19 INFECTION ${ }^{11-12}$}

Since the December 2019 outbreak of the novel coronavirus, also known as "COVID-19", in Wuhan, life has changed dramatically for many people. Many people are left confused and left with many questions about what they are to do to prevent the spread... In this article to provide information and guide according to WHO towards becoming a Community Immunity. A Community Immunity Ambassador is anyone who knows the steps to help themselves and help others to spread immunity throughout the community through accurate knowledge.

1. How respiratory infections are transmitted.

2. About the six elements of the "chain of infection" and how you can break that chain.

3. The strategies you and your loved ones can take to prevent spreading and contracting the virus.

\section{Viruses and Respiratory Infections ${ }^{13-17}$}

How respiratory infections, like COVID-19, are transmitted and what actions can take to prevent the spread of infections. A virus is a tiny infectious agent that is too small to be seen with the human eye or even under a normal microscope. They can only replicate and multiply if inside a living organism such as a human, animal, or plant which acts as the host. Respiratory viruses like to infect the lungs and airways. Respiratory infections tend to affect the normal function of the lungs causing breathing problems Figure 1.

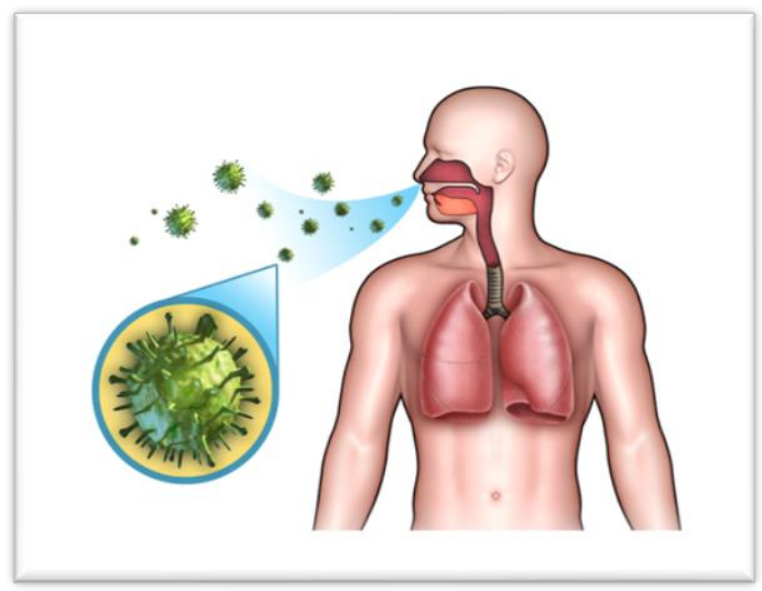

Figure 1: Respiratory infections

\section{WHAT IS COVID-19?}

COVID-19 is an infectious disease caused by the most recently discovered coronavirus (SARS-CoV-2). This new virus and disease were unknown before the outbreak began in Wuhan, China, in December 2019. The new coronavirus is spread from one person to another primarily through respiratory droplets generated when an infected person coughs or sneezes. According to recent reports, it may be possible that people infected with the novel coronavirus spread the virus before showing significant symptoms.
Some patients with confirmed infections with the novel coronavirus have showed little to no symptoms while others have become severely ill and died. Symptoms of infection include: Fever, cough and shortness of breath. At this time, it is believed that symptoms may appear in as few as 2 days or as long as 14 days after exposure.

Scientists are working hard to understand this new virus and produce a vaccine. Antibiotics do not work against viruses; they only work on bacterial infections. Therefore, antibiotics should not be used as a means of prevention.

\section{Modes of Transmission ${ }^{18-21}$}

A chain of infection refers to the path that viruses take to enter a person and to be transmitted from one person to another. There are six steps in the chain of infection and know that transmission will only take place if all six elements in the chain are present. That means, we can break the chain! Figure 2.

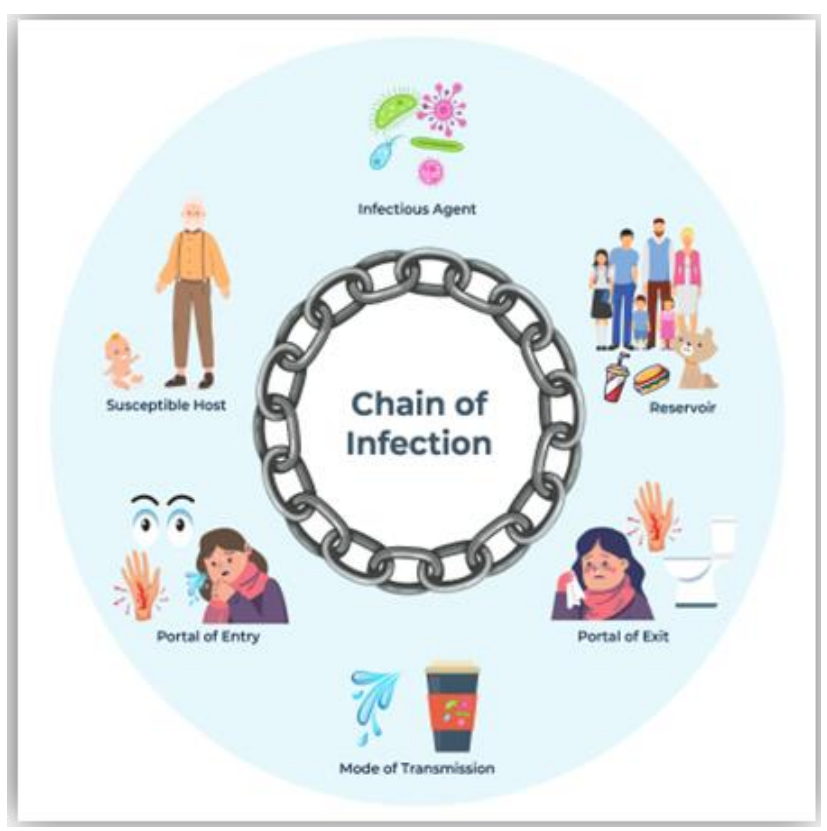

Figure 2: Six Elements in the Chain of Infection

\section{THE SIX ELEMENTS IN THE CHAIN OF INFECTION}

In order for an infection or disease to happen, six elements must be in place. This process is known as the chain of infection. The first element in the chain is an infectious agent, which can cause a disease. It could be a virus, bacteria, or fungi. The second element is the reservoir, or the place where the infectious agent lives. It can be a person, an animal, soil or water. Then we have a port of exit, which is the way the agent leaves the body. This can happen through the mouth, if a person coughs or sneezes, through a cut, if a person is bleeding, during diaper changes or toileting. The next element is the mode of transmission, which is how the infectious agent is transmitted from one person to another. It can be in form of droplets, direct or indirect contact, or through airborne transmission. The fifth element in the chain of infection is the port of entry, or the place where the infectious agent enters another person's body. This is similar to the port of 
exit, it can be a mouth, nose, eyes, an open cut etc. Finally, we have a susceptible host - it's either a baby, an elderly person or someone with a weakened immune system. To prevent the spread of the disease, one of the links in the chain of infection must be broken. Each and every one of us can do our part to slow and stop COVID-19 from spreading. Break the Chain of Infection.

\section{Protect and Prevent ${ }^{19-22}$}

Protect ourselves and our loved ones through simple and practical changes to our daily behaviors and routines.

- Practicing good hand hygiene (hand washing)

- $\quad$ Cough and sneeze etiquette

- Cleaning and disinfecting our environments
- Practicing social distancing

\section{Hand Hygiene}

Washing hands is one of the best ways to prevent from getting infected. Washing your hands frequently helps to remove potentially harmful microorganisms from hands. And this helps stop the spread of infection. The WHO (World Health Organization) recommends washing your hands by following the 7 steps; Rub plams together, rub the back of both hand, interface and rub hand together, interlock finger and rub the back of finger of both hand, rub thumb in a rotating manner followed by the area between index finger and thumb for both hands, rub fingertips on palm for both hands and last rub both wrists in a rotating manner. Rinse and dry thoroughly, shown (Fig. 3).

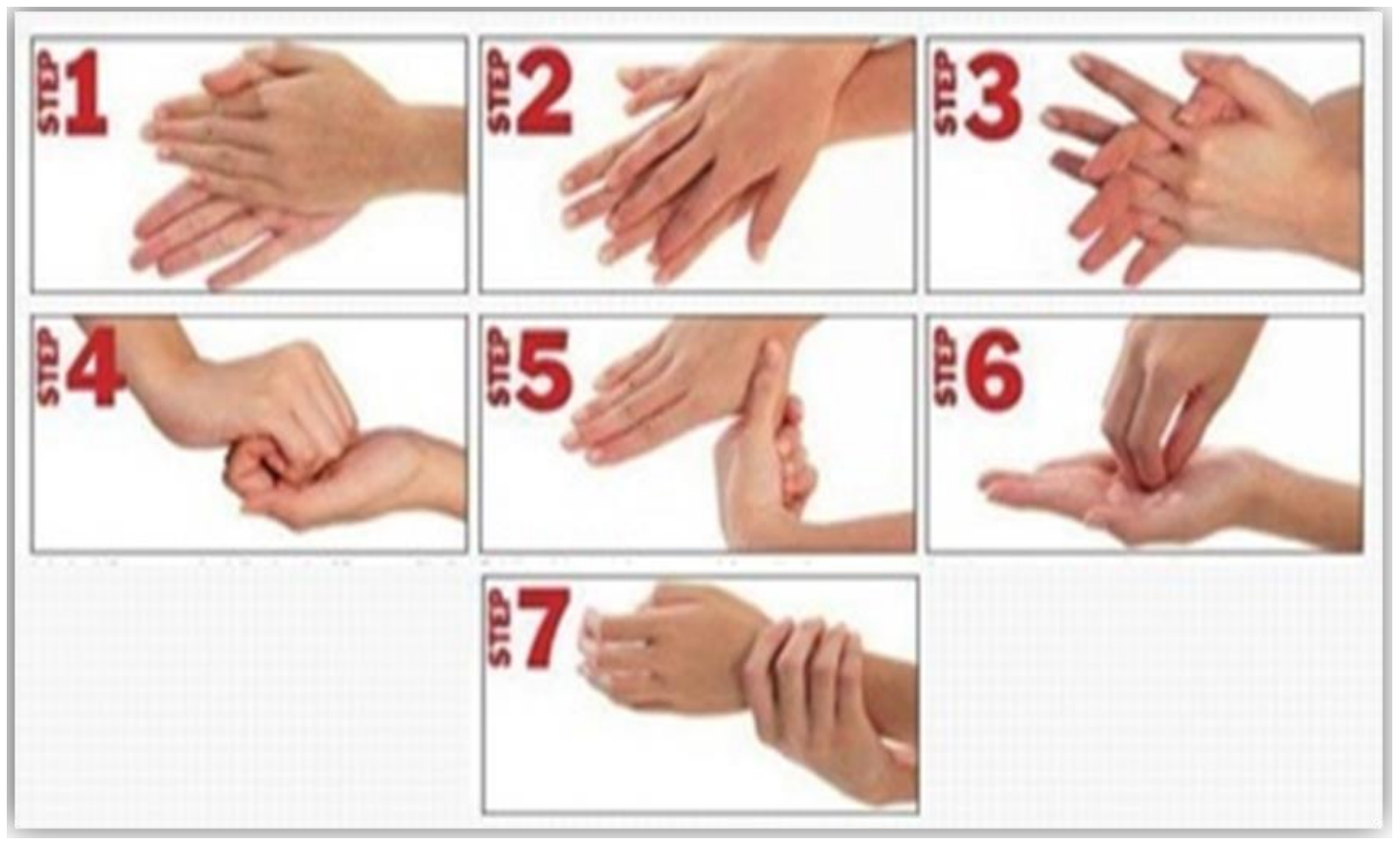

Figure 3: WHO recommends 7 steps for washing hands

\section{Hand Sanitizer ${ }^{23-26}$}

When you don't have access to soap and water, using hand sanitizer containing at least $60 \%$ alcohol is a great way to ensure your hands are clean. However, the best way to ensure sparkly clean hands is still by using soap and water for 20 seconds.

\section{Cough Etiquette}

Droplets from coughs and sneezes travel...ffar! This is why we must practice cough and sneeze etiquette. These simple steps can help to reduce the spread of COVID-19. Cover mouth and nose with a tissue when coughing or sneezing and dispose of the tissue immediately. If do not have a tissue, sneeze into your elbow rather than your hands. Wash hands with soap and water immediately.

\section{Cleaning Everyday Environment}

To break the chain and prevent infection, it is important to be more mindful about the surfaces we touch and to keep those surfaces clean. There are a number of ways to keep your surfaces clean and disinfected. And you probably already have some of these ways in the house!

\section{Simple bleach cleaning recipe}

Mix 3/4 cup Regular Bleach with one gallon of water. Using a rag or spray bottle, wash or wipe this solution onto surfaces. Allow solution to stand for at least 5 minutes. Rinse with regular water and let air dry. Use a regular household disinfectant or using an alcohol spray of at least $60 \%$ alcohol. Both can be purchased at any grocery store. And don't forget to clean your cell phone!

\section{Social Distancing 27-30}

Social distancing is a public health measure known to help stop or slow the spread of infectious diseases. This is especially important with COVID-19 because even those who do not show signs of illness may be sick and can spread the virus. 


\section{Ways to social distance include:}

- Closing schools and moving to distance learning

- Working from home

- Postponing or cancelling social events and travel

- Maintaining a physical distance of at least 2 meters between other people. If we stay at home and limit contact with others, we will slow the spread of COVID-19.

\section{What about face mask}

No doubt you have seen pictures or even people walking around wearing surgical or protective N95 masks. While this might seem like a good idea, wearing a mask in many cases does more harm than good to you and your community.

Healthcare workers are the only people who can help us get better when we are sick. Because of the current shortage of face masks in the world, healthcare workers are at increased risk of contracting COVID-19. If healthcare workers get sick, there will be no one to take care of the sick people, and COVID-19 may continue to spread.

\section{When to wear a mask...}

As a Community Immunity Ambassador, you can help to be part of the solution by urging others not to buy masks or protective gloves for their own use. These are a limited resource, desperately needed by our healthcare workers and the sick.

\section{You should only wear a mask if:}

You are a healthcare provider caring for potentially sick patients. You are sick or are caring for a family member who is sick. You are instructed to do so by your doctor or healthcare provider.

\section{What is a N95 Mask?}

An N95 mask is specially designed to filter airborne particles. It needs to be fitted properly to ensure its effectiveness.

Purpose: Prevent inhalation of airborne particles (that may contain infectious agents)

Usage: When there is air pollution such as haze, caused by minute particles in the atmosphere

N95 masks are recommended for healthcare workers.

\section{What Is a Surgical Mask?}

A surgical mask has 3 layers (3-ply) which serves different functions:

- Outer layer - fluid-repelling;

- Middle layer - barrier to microorganism entry; and

- Inner layer - moisture-absorbing.

Purpose: Provide barrier protection against droplets including large respiratory particles.
Usage: Protect both residents and healthcare professionals against possible respiratory infection.

Surgical masks are recommended for those who have infections or those looking after close contacts with infection at home Figure 4.

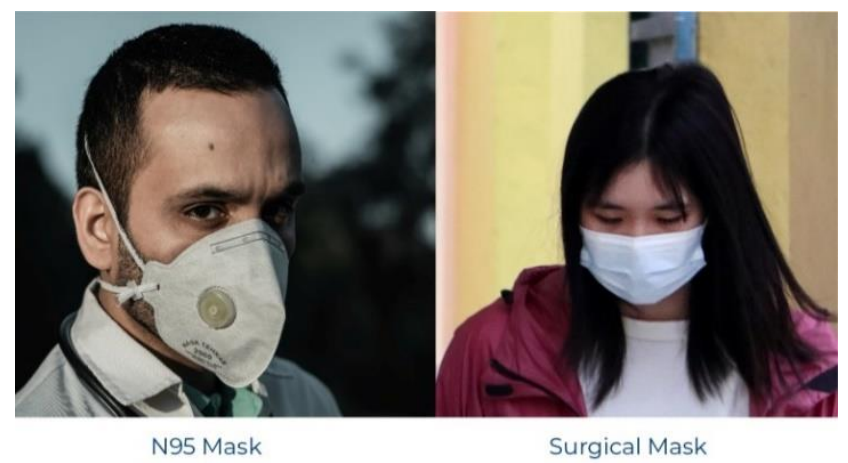

Figure 4: N95 Mask and Surgical Mask

\section{REFERENCES}

1. Centers for Disease Control and Prevention: coronavirus disease 2019 (COVID-19) - situation summary, 2020, Accessed: March 11, 2020.

2. Wang C, Horby PW, Hayden FG, Gao GF, A novel coronavirus outbreak of global health concern. Lancet, 2020.

3. WMHC. Wuhan Municipal Health and Health Commission's Briefing on the Current Pneumonia Epidemic Situation in Our City, 2020.

4. Li Q, Guan X, Wu P, Wang X, Zhou L, Tong Y, et al., Early transmission dynamics in Wuhan, China, of novel coronavirus infected pneumonia. N Engl J Med, 2020.

5. CDC. 2019 Novel coronavirus, Wuhan, China, 2020.

6. Centers for Disease Control and Prevention: human coronavirus types, 2020.

7. WHO. Novel Coronavirus-Japan (ex-China), 2020.

8. Virological. org. Novel 2019 Coronavirus Genome 2020.

9. Fehr AR, Channappanavar R, Perlman S, Middle East respiratory syndrome: emergence of a pathogenic human coronavirus. Annu Rev Med, 68, 2017, 387-99.

10. WHO. Statement on the second meeting of the International Health Regulations (2005) Emergency Committee regarding the outbreak of novel coronavirus (2019-nCoV), 2020.

11. Aiello, A.E., Coulborn, R.M., Perez, V., Larson, E.L. Effect of hand hygiene on infectious disease risk in the community setting: a meta-analysis. Am. J. Publ. Health. 2008, 98.

12. Rabie, T., Curtis, V, Hand washing and risk of respiratory infections: a quantitative systematic review. Trop. Med. Int. Health, 2006, 11. 
13. 4. Chang CK, Lo SC, Wang YS, Hou MH, Recent insights into the development of therapeutics against coronavirus diseases by targeting $N$ protein. Drug Discov Today, 21, 2016, 562-72.

14. Paules $\mathrm{Cl}$, Marston HD, Fauci AS, Coronavirus infections-More than just the common cold. JAMA, 323, 2020, 707.

15. Guo Y, Korteweg C, McNutt MA, Gu J. Pathogenetic mechanisms of severe acute respiratory syndrome. Virus Res., 2008, 133:4-12.

16. Gu J, Korteweg C, Pathology and pathogenesis of severe acute respiratory syndrome. Am J Pathol., 170, 2007, 1136-47.

17. Ding $Y$, He L, Zhang Q, Huang Z, Che X, Hou J, et al., Organ distribution of severe acute respiratory syndrome (SARS) associated coronavirus (SARS-CoV) in SARS patients: Implications for pathogenesis and virus transmission pathways. J Pathol., 203, 2004, 622-30.

18. Jin YH, Cai L, Cheng ZS, et al., A rapid advice guideline for the diagnosis and treatment of 2019 novel coronavirus [2019-nCoV] infected pneumonia [standard version]. Mil Med Res. 7, 2020, 4.

19. World Health Organization. Coronavirus disease [COVID-19] Technical Guidance: Infection Prevention and Control.

20. Chang D, Xu H, Rebaza A, Sharma L, Dela Cruz CS, Protecting health-care workers from subclinical coronavirus infection. Lancet Respir Med, 2020.

21. Li J, Li J, Xie X, et al., Game consumption and the 2019 novel coronavirus. Lancet Infect Dis., 2020.

22. Centers for Disease Control and Prevention: coronavirus disease 2019 (COVID-19) - how to protect yourself, 2020.
23. World Health Organization, 2009. Hand Hygiene as a Performance Indicator. World Health Organization, Geneva, 2009, pp. 1.

24. Wolf J, Hunter PR, Freeman MC, Cumming O, Clasen $T$, Bartram J, Higgins JPT, Johnston R, Medlicott K, Boisson $S$, Pruss-Ustun A. Impact of drinking water, sanitation and handwashing with soap on childhood diarrhoeal disease: updated meta-analysis and meta-regression. Trop. Med. Int. Health, 23 (5), 2018, 508-525.

25. Cairncross S, Hunt C, Boisson S, Bostoen K, Curtis V, Fung IC, Schmidt WP. Water, sanitation and hygiene for the prevention of diarrhoea. Int. J. Epidemiol, 2010, 39 (Suppl. 1), i193-i205.

26. Freeman $M C$, Stocks, $M E$, Cumming $O$, Jeandron $A$, Higgins J, Wolf J, Prüss-Ustün A, Bonjour S, Hunter PR, Fewtrell L. Systematic review: hygiene and health: systematic review of handwashing practices worldwide and update of health effects. Trop. Med. Int. Health, 2014, 19.

27. National Health Commission of People's Republic of China. Guidelines for public protection against novel coronavirus infection, 2020.

28. Griffiths J, Woodyatt A. Wuhan CoV death toll from Wuhan coronavirus tops 100 as infection rate accelerates. CNN Website, 2020.

29. Griffiths J, Woodyatt A. China goesinto emergency mode as number of confirmed Wuhan coronavirus cases reaches 2700. CNN website, 2020.

30. WHO. Advice on the use of masks in the community, during home care and in health care settings in the context of the novel coronavirus 2019-nCoV outbreak (Interim guidance).

Source of Support: None declared.

Conflict of Interest: None declared.

For any question relates to this article, please reach us at: editor@globalresearchonline.net New manuscripts for publication can be submitted at: submit@globalresearchonline.net and submit_ijpsrr@rediffmail.com 